\title{
Review
}

\section{Mental Health and Physical Activity among Children and Adolescents during the COVID-19 Pandemic}

\author{
Junko Okuyama, ${ }^{1,2}$ Shuji Seto, ${ }^{2,3}$ Yu Fukuda, ${ }^{4}$ Shunichi Funakoshi, ${ }^{5}$ \\ Shintaro Amae, ${ }^{6}$ Jun Onobe, ${ }^{7}$ Shinichi Izumi, ${ }^{1}$ Kiyoshi Ito ${ }^{2,3}$ and \\ Fumihiko Imamura ${ }^{2,3}$ \\ ${ }^{1}$ Department of Physical Medicine and Rehabilitation, Tohoku University Graduate School of Medicine, Sendai, \\ Miyagi, Japan \\ ${ }^{2}$ Core Research Cluster of Disaster Science, Tohoku University, Sendai, Miyagi, Japan \\ ${ }^{3}$ International Research Institute of Disaster Science (IRIDeS), Tohoku University, Sendai, Miyagi, Japan \\ ${ }^{4}$ Notre Dame Seishin University, Okayama, Okayama, Japan \\ ${ }^{5}$ Miyagi Psychiatric Center, Natori, Miyagi, Japan \\ ${ }^{6}$ Sendai Ekoh Medical and Rehabilitation Center for Persons with Severe Motor and Intellectual Disabilities, \\ Sendai, Miyagi, Japan \\ ${ }^{7}$ Department of Rehabilitation, Faculty of Medical Science and Welfare, Tohoku Bunka Gakuen University, \\ Sendai, Miyagi, Japan
}

Coronavirus disease 2019 (COVID-19) is causing disruptions in the global social system. Japanese children and adolescents have had their schools closed, government-mandated activity restrictions imposed, and interactions outside the home reduced. These restrictions can have a considerable psychological impact on children and adolescents. This review aims to describe the impacts of COVID-19 pandemic on physical activity and psychological status of this population. The review was conducted by searching PubMed for information on the impact of COVID-19-related activity restrictions on children and adolescents. The search identified 11 articles, three of which contained data on anxiety and psychological problems due to physical inactivity. Next, a PubMed search was conducted about physical activity and psychological status in children and adolescents under psychological stress. The search identified 368 articles, 28 of which were included in the review. For children, data that revealed a correlation between physical activity and psychological health and sedentary time leading to mood disorders were included. For adolescents, there were nine studies that reported a correlation between physical activity and psychological health and four studies that reported no correlation between physical activity and psychological health. Of the studies that reported a correlation, seven reported that physical activity improves psychological health. The impact of psychologically stressful situations such as COVID-19 on children and adolescents has been experienced worldwide. Physical activity has been correlated with psychological health, and it may improve psychological status; physical activity should be recommended to better support the psychological health of children and adolescents under the influence of COVID-19.

Keywords: coronavirus disease 2019 (COVID-19) pandemic; disaster medicine; mental health; physical activity; school restriction

Tohoku J. Exp. Med., 2021 March, 253(3), 203-215.

\section{Introduction}

Coronavirus disease 2019 (COVID-19) caused by severe acute respiratory syndrome coronavirus-2 (SARS-
CoV-2) has posed a significant threat to health globally (Zhou et al. 2020b; Wang and Xu 2020). In December 2019, this new coronavirus began its spread in Wuhan, Hubei Province, China, and by February 13, 2021, it had

Received September 25, 2020; revised and accepted February 15, 2021. Published online March 26, 2021; doi: 10.1620/tjem.253.203.

Correspondence: Junko Okuyama, M.D., Ph.D., Department of Physical Medicine and Rehabilitation, Tohoku University Graduate School of Medicine, 2-1 Seiryo-machi, Aoba-ku, Sendai, Miyagi 980-8575, Japan.

e-mail: junko.okuyama@med.tohoku.ac.jp

(C)2021 Tohoku University Medical Press. This is an open-access article distributed under the terms of the Creative Commons Attribution-NonCommercial-NoDerivatives 4.0 International License (CC-BY-NC-ND 4.0). Anyone may download, reuse, copy, reprint, or distribute the article without modifications or adaptations for non-profit purposes if they cite the original authors and source properly.

https://creativecommons.org/licenses/by-nc-nd/4.0/ 
infected more than $108,762,911$ people worldwide (COVID-19 Coronavirus Pandemic: https://www.worldometers.info/coronavirus).

In this review, physical activity, and psychological state under stress, such as COVID-19 lockdown, were examined in children and adolescents. By reviewing research on COVID-19 that is currently affecting children and adolescents, as well as previous research on children and adolescents under similar stress, we believe that we can better understand the current psychological state of children and adolescents and use this information to support them.

\section{The impact of COVID-19 lockdowns on children and adolescents}

The lockdowns began in China and continued in the United Kingdom, India, and Spain. In Japan, however, school closures and activity restrictions were imposed in the form of self-restraints rather than a lockdown.

As shown in Fig. 1, nationwide lockdown measures were first implemented by the Chinese central government on January 23, 2020, which brought Chinese society almost to a standstill (Fu et al. 2021; Bao and Zhang 2020). Next, lockdowns began in March 2020 in the UK and Peru (weeks 11 and 12 of 2020 in the UK; March 16-28 in Peru (Kwok et al. 2020; Montano and Gushiken 2020). India,
Spain, and Australia also began lockdowns in March 2020, but the lockdown period was long, continuing until June (Naqvi et al. 2021; Picchio et al. 2020; Wang et al. 2020b). In New Zealand and Urban Ghana in sub-Saharan Africa, the lockdown period was almost the entire month of April. In contrast, Latin America had implemented stringent lockdowns for more than three months, since the second half of March 2020 (Chen et al. 2020). The COVID-19 pandemic resulted in physical isolation measures in many parts of the world (Gallo et al. 2020). The enforcement of extremely strict pandemic prevention measures worldwide (e.g., the mandatory closure of schools and the suspension of all nonessential commercial activities) seriously affected people's daily life and work activity, and placed many for-profit organizations at risk of failure (Ayittey et al. 2020).

Japan has been trying to control the spread of COVID19 since early 2020 through a policy encouraging the public to avoid "closed spaces, crowded places, and close-contact settings," instead of through a complete lockdown (Karako et al. 2020). Further, the Japanese government requested that all primary and secondary schools close temporarily from early March, declared states of emergency in April, and lifted them in late May (Inada et al. 2021).

\begin{tabular}{|c|c|c|c|c|c|c|c|}
\hline & January & February & March & April & May & June & $\begin{array}{c}\text { Author } \\
\text { Date of } \\
\text { publication }\end{array}$ \\
\hline China & & & & & & & $\begin{array}{c}\text { Fu et al. } \\
2020 \text { Oct } 27\end{array}$ \\
\hline England & & & & & & & $\begin{array}{l}\text { Kwok et al. } \\
2020 \text { Nov } 3\end{array}$ \\
\hline India & & & & & & & $\begin{array}{l}\text { Naqvi et al. } \\
2020 \text { Oct } 27\end{array}$ \\
\hline Spain & & & & & & & $\begin{array}{l}\text { Picchio et al. } \\
2020 \text { Nov } 4\end{array}$ \\
\hline Peru & & & & & & & $\begin{array}{c}\text { Montano \& Gushiken } \\
2020 \text { Oct }\end{array}$ \\
\hline Australia & & & & & & & $\begin{array}{l}\text { Wang et al. } \\
2020 \text { Oct } 29\end{array}$ \\
\hline New Zealand & & & & & & & $\begin{array}{c}\text { Every-Palmer et al. } \\
2020 \text { Nov } 4\end{array}$ \\
\hline Latin America & & & & & & & $\begin{array}{l}\text { Chen et al. } \\
2020 \text { Nov } 2\end{array}$ \\
\hline $\begin{array}{l}\text { Urban Ghana, sub- } \\
\text { Saharan Africa }\end{array}$ & & & & & & & $\begin{array}{l}\text { Amewu et al. } \\
2020 \text { Oct } 30\end{array}$ \\
\hline Tokyo, Japan & & & & & & & $\begin{array}{c}\text { Karako et al. } \\
2020 \text { Sep }\end{array}$ \\
\hline
\end{tabular}

Fig. 1. Global COVID-19 related lockdown of 2020.

The top row shows the month of 2020. The left column shows the respective countries in COVID-19-related lockdown. The horizontal bars indicate the duration of the lockdown.

The periods of lockdown for each country were as follows; China: from January 24 to February 9, 2020; England: 11th/12th week in 2020; India: March 24, 2020 for three weeks up to April 14, later extended until the end of June; Spain: March 14-June 21, 2020; Peru: March 16-28, 2020; Australia: March 15-June 1, 2020 and from June 30, 2020; New Zealand: March 25-April 28, 2020 (33 days); Latin America: more than three months since the second half of March 2020; Urban Ghana in sub-Saharan Africa.

Period of restraint below the horizontal line: Instead of a complete lockdown, Japan instigated a self-restraint request policy of three weeks' duration in April 2020 and Tokyo, Japan from March 1-July 31, 2020. 
The psychological and physical effects of a lockdown

Regardless of the effectiveness of such measures in controlling an outbreak, the psychological effects of a widespread contagion and lockdown are inevitable (Rubin and Wessely 2020). A pandemic and related containment measures - namely quarantine, social distancing, and self-isolation-can have a detrimental impact on mental health (Marazziti and Stahl 2020). In a study of the initial phase of the COVID-19 outbreak in China, more than half of the respondents rated the psychological impact as moderate-tosevere in response to the occurrence of the contagion, and approximately one-third of the respondents reported moderate-to-severe anxiety (Wang et al. 2020a). Similar data have been reported in Japan. For example, Shigemura et al. (2020) suggested that fear of emerging infectious diseases raises anxiety levels in healthy individuals and may manifest as a range of psychological, behavioral, and/or psychosomatic conditions. As an integral part of COVID-19 response, mental health needs should be addressed (Fiorillo et al. 2020).

Simultaneously, the lockdown may have reduced individual physical activity. This is a serious concern because negative psychological effects of prolonged periods of physical inactivity have been reported. The lockdown issued by the Spanish government due to the outbreak of the COVID-19 forced the Spanish population to self-isolate at home. Carriedo et al. (2020) showed that individuals who regularly engaged in vigorous physical activity during the first week of confinement reported higher resilience in terms of higher locus of control, higher self-efficacy, and higher optimism. Additionally, Maugeri et al. (2020) showed that quarantine in Italy induced a significant reduction in total weekly physical activity energy expenditure in all age groups, and this reduction negatively affected psychological well-being.

\section{Global impact of the COVID-19 related lockdown on children and adolescents}

Social isolation due to COVID-19 caused significant disruption of daily routines for the global community, especially children. Most schools were closed, classes were cancelled, and learning became home-based or online to encourage adherence to social distancing guidelines, with the goal of restricting the spread of the virus (Shah et al. 2020). As shown in Fig. 2, headaches and migraine symptoms improved during the lockdown because of relief from school-related stressors (Papetti et al. 2020; Dallavalle et al. 2020). Inappropriate use of pediatric emergency care appeared to have reduced (Keays et al. 2020; Vierucci et al. 2020). Type 1 diabetes among children appeared to have worsened during the lockdown period due to lifestyle changes (Brener et al. 2020) but stabilized through medical care (Ceconi et al. 2020; Passanisi et al. 2020).

Twenty-five articles and reviews were found on the impact of the COVID-19 related lockdown on the mental health of children and adolescents. It has been shown that companionship is essential for children's normal psychological development and well-being (World Health Organization 2004). Townsend (2020) suggested that the COVID-19 pandemic lockdown response has had a disproportionate and damaging effect on the lives, mental health, and well-being of young people globally. Young people have been neglected in policymaking, and their needs have been subjugated to those of adults, which contravenes the UN Convention on the Rights of the Child. Spanish children were locked down for 72 days due to COVID-19. After lockdown, adolescents' problems increased signifi-

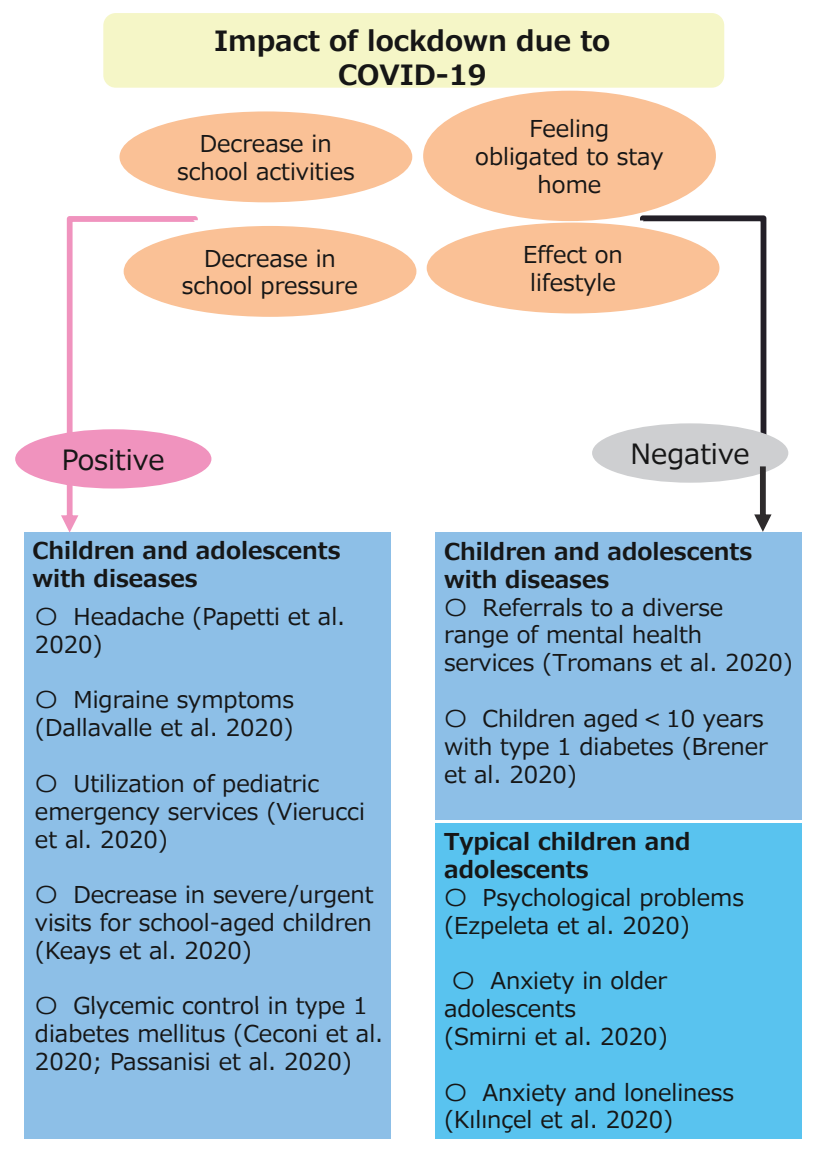

Fig. 2. The Effects of COVID-19 related lockdown on children and adolescents under psychological stress. The "Positive Effect" column indicates studies that reported a positive effect due to COVID-19-lockdown. The "Negative Effect" column indicates studies that reported a negative effect due to COVID-19-lockdown. The box "Diseases that children and adolescents had before lockdown" indicates studies of children and adolescents with disease. Six studies indicated that the lockdown had a positive effect on headaches, including improvements in headaches due to reduced school effort and anxiety. Two studies showed that lockdown had negative effects, including changes in lifestyle.

The box "Mental health" denotes studies of normal children and adolescents. None of the studies showed a positive effect of lockdown. Three studies showed that lockdown had a negative impact, including a decrease in physical activity. 
cantly compared to pre-lockdown, in terms of conduct, peer relationships, prosocial behavior, and problems overall, with effect sizes ranging from small to medium (Ezpeleta et al. 2020).

Sicilian study reported that the lockdown negatively affected physical activity, with greater impacts on men and overweight persons (Giustino et al. 2020). A decrease in physical activity was expected because of social distancing (Gilic et al. 2020). It is also important for children and adolescents to participate in and enjoy physical activity during their leisure time (Shahidi et al. 2020). According to a review by Biddle and Asare (2011), evidence shows small but consistent associations between sedentary screen time and poor mental health. The World Health Organization (2010) recommends that children and adolescents aged 5-17 years should engage in at least 60 minutes of moderate to vigorous intensity physical activity per day.

Regarding restriction of school activities, even shortterm shutdown of educational institutions and/or being forced to stay home are troublesome for children and adolescents (Stewart et al. 2018; Lee 2020); such situations predict detrimental effects on their physical and mental health, such as diminished sense of normality-schools tend to provide such normality. Additionally, little is known regarding the long-term effects of large-scale disease outbreaks on the health and well-being of children and adolescents (Lee 2020). The damage that such situations cause in children and adolescents may result in the development of post-traumatic disorder (PTSD), which can be a highly persistent mental health issue (Bolton et al. 2000; Hiller et al. 2016; Yule et al. 2000; Morgan et al. 2003; Goenjian et al. 2018). It has been shown that PTSD in children and adolescents is associated with the development of other psychological problems (Udwin et al. 2000) and/or associated with decreased quality of life (Khachadourian et al. 2015).

\section{Impact of the COVID-19 related restrictions on children and adolescents in Japan}

In Japan, as of February 12, 2021, 408,327 people have been infected with and 6,772 have died with COVID19 (Ministry of Health, Labour, and Welfare 2020). Instead of complete lockdown, since the outbreak of COVID-19, Japan has been trying to control infection through a policy of self-restraint calling for avoidance of "closed spaces, crowded places, and close-contact settings" to the greatest extent possible (Karako et al. 2020). Additionally, on March 2, 2020, the Japanese government requested elementary, junior high, and high schools nationwide to give temporary leave after spring break. Furthermore, the Japanese government declared a state of emergency on April 7, 2020, which forced all prefectures to take emergency/precautionary measures against the pandemic by April 16, 2020. This led to most Japanese schools closing temporarily until the end of May (Ministry of Education, Culture, Sports, Science and Technology, Elementary and Secondary Education Bureau, Health Education and Food Education
Division 2020).

On May 25, 2020, the Japanese government lifted the state of emergency in the whole country; thus, allowing for the reopening of schools nationwide. Nonetheless, some measures were enforced owing to the pandemic: Students had to wear face masks, use different entrances, and line up in front of teachers - while keeping safe distances from one another - to permit the latter to check their temperatures prior to class onset (Kyodo News 2020).

However, a search on PubMed on February 13, 2021 showed that there was only one report of the impact on children and adolescents in Japan of the restrictions on school life for COVID-19 epidemic prevention. The study suggests that the first wave of the COVID-19 pandemic has not significantly affected suicide rates among children and adolescents during the school closure in Japan (Isumi et al. 2020). A search on February 13, 2021 for "Japana Centra Revuo Medicina Web" raised concerns that the restrictions of school life could interfere with children and adolescents' ego independence by keeping children, adolescents, and parents in their homes (Shibata 2020), but no data to support this claim were available.

\section{Study Design and Findings}

The electronic database PubMed were searched in November 2020 using terms "mental health" [MeSH] AND ("child" [MeSH] OR "adolescent" [MeSH]) AND ("exercise" [MeSH]) (Fig. 3). In Japan, this was the time of the third wave of the COVID-19 epidemic, but schools were not closed as they were during the first and second waves. During this period, the effects of COVID-19 on the mental health of children and adolescents were being considered based on past findings.

Articles (including short reports) on physical activity and mental health content were reviewed. No dates, languages, or study designs were considered as exclusion criteria. Only primary research articles were deemed eligible and reviews were excluded.

A previous meta-analysis suggested that physical activity interventions can improve adolescents' mental health; however, additional studies are needed to confirm the effects of physical activity on children's mental health. Findings from observational studies suggest that promoting physical activity and decreasing sedentary behavior might protect mental health in children and adolescents (PROSPERO Registration Number: CRD42017060373; Rodriguez-Ayllon et al. 2018).

This work focuses on the relationship between physical activity and mental health in children and adolescents during lockdown due to the COVID-19 pandemic, as reported in previous studies. Thus, the word "COVID-19" was added as a search term. After the eligibility assessment, 11 studies were included and analyzed. Furthermore, researchers have argued that the mental health of children and adolescents under stress is different from the normal state; thus, we added the term "psychological stress" to the 


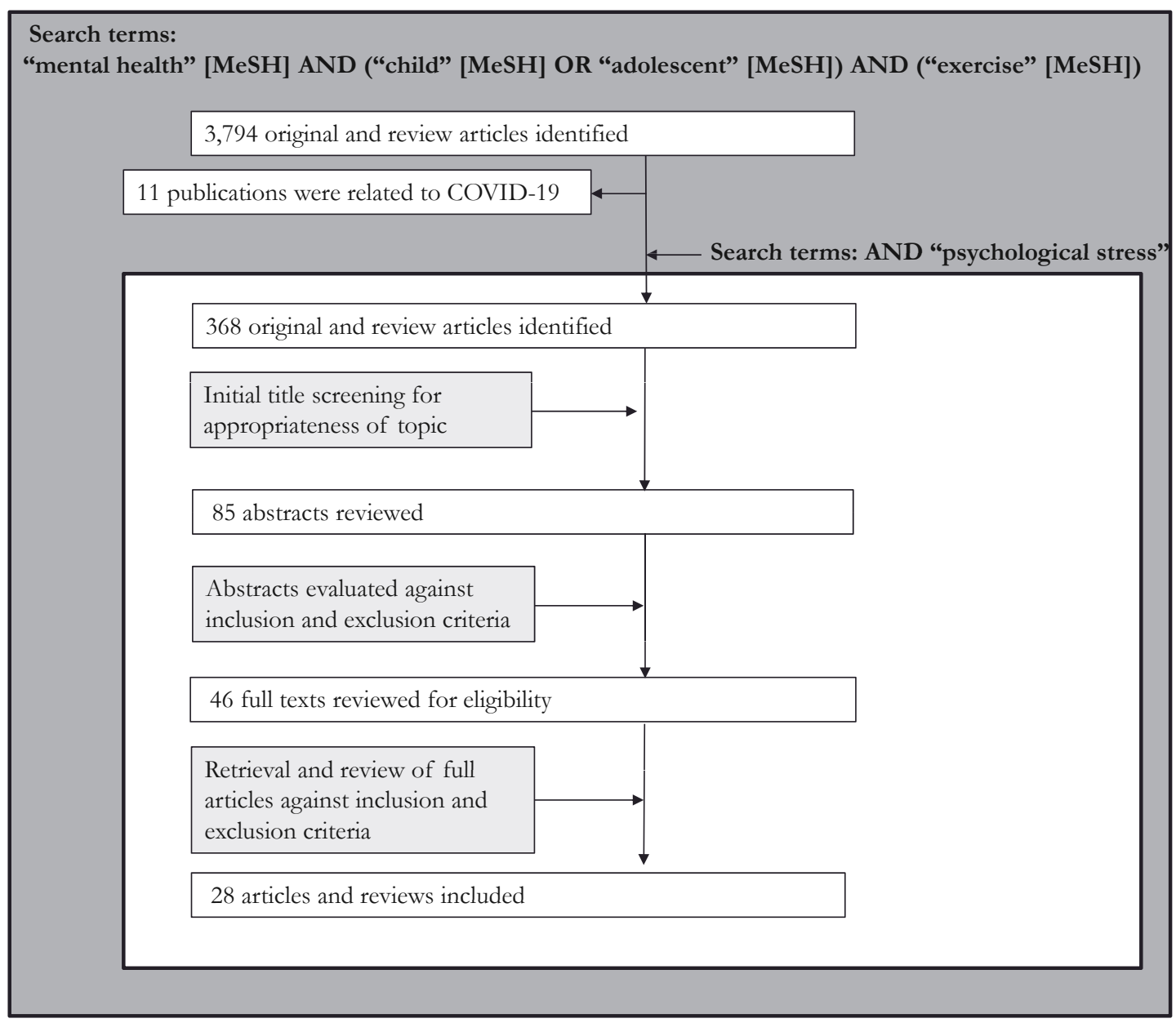

Fig. 3. A search was conducted of PubMed for studies addressing physical activity and mental health of children and adolescents.

The PubMed database was searched on November 5, 2020 using the keywords children (AND, OR) adolescents, and physical activity and mental health. A total of 3,794 studies were identified, of which 10 related to COVID-19. Based on the studies, we used keywords related to psychological stress. Three hundred and sixty-eight studies were selected by title. Abstracts of 85 studies were reviewed. Forty-six full-text studies were included. Finally, 28 studies were selected for analysis.

"mental health" [MeSH] AND ("child" [MeSH] OR "adolescent" [MeSH] ) AND (“exercise" [MeSH] ) search results. Finally, after the eligibility assessment, 28 studies were included and analyzed (Fig. 3).

Due to variations in methodology and a small final sample size, meta-analysis was not possible (Fig. 3). Data extraction and review of the main themes, research methods, and findings were undertaken. A data extraction tool was formulated based on current literature and objectives. The following information was extracted from each research article, (1) authors, (2) year of publication, (3) title, (4) definition of mental health, (5) definition of physical activity, (6) participants, (7) methods, and (8) results. After collection, the data were reviewed and a comparison between papers was conducted to examine differences and similarities.
Mental health and physical activity under COVID-19 infectious disease pandemic

A PubMed search for "mental health" [MeSH] AND ("child" [MeSH] OR "adolescent" [MeSH]) AND ("exercise" [MeSH]) AND ("exercise" [MeSH]) and COVID-19 yielded 11 results, four of which were research papers (Table 1). Three of the four studies were from China (Deng et al. 2020; Zhang et al. 2020; Zhou et al. 2020a) and the remaining were from Spain (López-Bueno et al. 2020). Decrease in physical activity during the COVID-19 related lockdown period was reported in three studies (LópezBueno et al. 2020; Zhang et al. 2020; Zhou et al. 2020a). Two of these studies in China (Zhang et al. 2020; Zhou et al. 2020a) reported that reduced physical activity led to worsening mood. Deng et al. (2020) showed that reduced physical activity correlated with worse mood. 
Table 1. Characteristics of the included articles on children and adolescents under COVID-19-related stress.

\begin{tabular}{|c|c|c|c|c|}
\hline Participants & Site & Physical activity & Mental health & Authors \\
\hline $\begin{array}{l}\text { Children and } \\
\text { adolescents }\end{array}$ & $\begin{array}{l}\text { Yan'an, } \\
\text { China }\end{array}$ & $\begin{array}{l}\text { Moderate-to-vigorous } \\
\text { physical activity }\end{array}$ & Mood states & $\begin{array}{l}\text { Zhang et } \\
\text { al. (2020) }\end{array}$ \\
\hline $\begin{array}{l}\text { School-aged children } \\
\text { and adolescents }\end{array}$ & Spain & $\begin{array}{l}\text { Weekly minutes of } \\
\text { physical activity }\end{array}$ & & $\begin{array}{l}\text { López- } \\
\text { Bueno et } \\
\text { al. (2020) }\end{array}$ \\
\hline College students & $\begin{array}{l}\text { Wuhan, } \\
\text { China }\end{array}$ & $\begin{array}{l}\text { Regular and sufficient } \\
\text { exercise }\end{array}$ & Mental status & $\begin{array}{l}\text { Deng et al } \\
(2020)\end{array}$ \\
\hline $\begin{array}{l}\text { Female adolescents } \\
\text { aged } 11-18 \text { years }\end{array}$ & $\begin{array}{l}\text { Mainland } \\
\text { China }\end{array}$ & $\begin{array}{l}\text { Physical exercise } \\
\text { duration }\end{array}$ & $\begin{array}{l}\text { Experiencing } \\
\text { depression }\end{array}$ & $\begin{array}{l}\text { Zhou, } \\
\text { Yuan et al. } \\
(2020)\end{array}$ \\
\hline
\end{tabular}

Four articles were obtained from a search on physical activity and mental health under the influence of COVID-19. Three of the studies showed a decrease in physical activity because of COVID-19. Two of the studies stated that mental health deteriorated due to decreased physical activity as a result of COVID-19. Deng et al. (2020) said there is a correlation between college students' usual physical activity and mental health.

\section{Studies with child samples}

Regarding children under stress due to COVID-19, previous studies on physical activity and the mental health of children under stress were examined. In total, three articles examined physical activity and mental health in children under psychological stress (Martikainen et al. 2013; Culver et al. 2015; Thompson et al. 2020). Two out of the three studies (Culver et al. 2015; Tonorezos et al. 2019) found an association between physical activity and mental health, as shown in Fig. 4. In Haiti, Culver et al. (2015) conducted a study among 76 children aged 7-17 years living in orphanages, showing that an 8-week yoga/dance classes may have evoked a reduction in trauma-related and EBD-related (i.e., emotional, and behavioral disorderrelated) symptoms; nonetheless, this finding was not statistically significant ( $p>0.05$; Culver et al. 2015). Vigorous exercise was assessed using the item, "On how many of the past 7 days did you exercise or participate in sports for at least 20 minutes that made you sweat or breathe hard (e.g., dancing, jogging, basketball, etc.)?" (Tonorezos et al. 2019).

The remaining study reported that sedentary time caused deterioration in mood (Endrighi et al. 2016), as shown in Fig. 4.

\section{Studies with adolescent samples}

Regarding adolescents under stress due to COVID-19, previous studies on physical activity and mental health of adolescents under stress were examined. In total, 23 articles examined physical activity and mental health in adolescents under psychological stress. Nine studies revealed a relationship between physical activity and mental health, as shown in Fig. 4. Five of the papers discussed the relationship between physical activity and psychological distress (Caldwell et al. 2011; Vankim and Nelson 2013; Zhao et al.
2013; Kleppang et al. 2019; Thompson et al. 2020), while the remaining four discussed sedentary time and mood deterioration (Padrón et al. 2012; Sloan et al. 2013; Tajik et al. 2017; Vandendriessche et al. 2019). Seven papers stated that physical activities improved mental health. Six of the studies discussed the relationship between physical activity and psychological distress (Jewett et al. 2014; Costigan et al. 2016; Duberg et al. 2016; Chu et al. 2018; Paolucci et al. 2018; Phillips et al. 2019), while the remaining discussed sedentary time and mood deterioration (Endrighi et al. 2016).

One study considered an aerobic exercise program, resistance, and aerobic program, and control delivered during physical education lessons or at lunchtime, three times per week for 8 weeks (Costigan et al. 2016).

Four studies found no link between physical activity and mental health (Holmes et al. 2016; Sagatun et al. 2016; Gotink et al. 2017; Opdal et al. 2019). Opdal et al. (2019) suggested that the effect of physical activity on mental health seems to be present in adulthood, but not in adolescence; in their assessment, physical activity may play different roles in these two life periods.

\section{Discussion}

We conducted a review to estimate the prevalence of changes in the physical activity and mental health of children and adolescents due to the COVID-19 related lockdown. Based on our results, we estimate that the COVID19 related lockdown affected the physical activity of children and adolescents negatively, namely, fewer were allowed/had the opportunity to achieve sufficient levels of physical activity. 


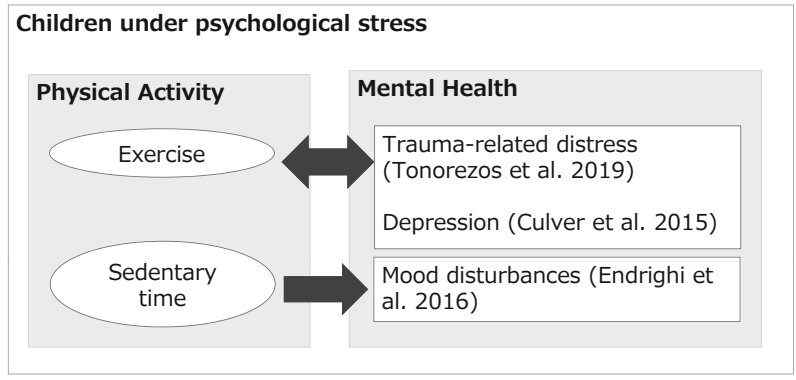

Adolescents under psychological stress

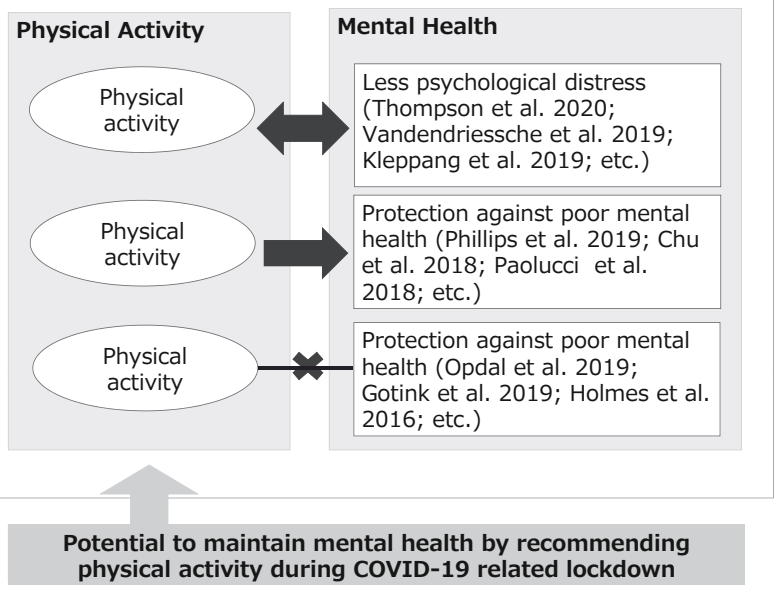

Fig. 4. Previous research on physical activity and mental health of children and adolescents under psychological stress.

"Children under psychological stress" shows studies of physical activity and mental health under psychological stress and the respective authors. Two of the three studies found a link between physical activity and mental health, and one study found that sedentary time leads to mood disturbances.

"Adolescents under psychological stress" shows studies of physical activity and mental health under psychological stress and the respective authors. Nine of the twenty studies found a link between physical activity and mental health, and one study found that sedentary time leads to mood disturbances. Seven studies found physical activities, such as dancing and school sports, led to improvement in mental health.

\section{Findings of previous research on physical activity and} mental health

Many previous studies, such as Buchanan and Keats (2011), reported that exercise is one of the most useful coping strategies after trauma and disastrous events. Despite many reports that physical activity has a significant correlation with mental health among children and adolescents under psychological stress (Sagatun et al. 2007; Zhao et al. 2013; Sloan et al. 2013; Culver et al. 2015; Duberg et al. 2016; Endrighi et al. 2016; Phillips et al. 2019; Tajik et al. 2017; Lucas-Thompson et al. 2019; Tonorezos et al. 2019; Vandendriessche et al. 2019), our review also demonstrated that some studies found no such correlation (Holmes et al. 2016; Opdal et al. 2019). Highlighting a possible explanation for this inconsistency in the literature, Opdal et al.
(2019) indicated that prior studies had utilized self-report measurements to assess physical activity, which may have led to inaccurate results. Corroborating this suggestion, Slootmaker et al. (2009) showed that, on average, adolescents' self-reports demonstrated that they spent 9 hours more in moderate physical activity per week and almost 3 hours more in vigorous activity per week compared with the numbers assessed by an accelerometer; namely, the adolescents overestimated their physical activity.

Children and adolescents experiencing restrictions to school life like those due to the COVID-19 pandemic

A search of PubMed in November 2020 showed that there have been no reports on the impact of the restricted school life during COVID-19 on children and adolescents in Japan. However, a search for restrictions on school life in Japan revealed reports of elementary school children in Fukushima after the Great East Japan Earthquake (Nomura et al. 2016).

After the Great East Japan Earthquake 2011, Japanese children and adolescents living in Fukushima faced restrictions in physical activity because although the area itself was not affected by the tsunami that accompanied the earthquake (which destroyed the environment to a significant extent), it was affected by radiation (Seto et al. 2019; Seto and Imamura 2020). Two studies provided two relevant findings: Time spent outdoors was positively associated with greater levels of overall physical activity, and adolescents living in disadvantaged neighborhood environments had limited opportunities for outdoor play (Karsten 2005; Kepper et al. 2020).

Oe et al. (2018) and Itagaki et al. (2017) also analyzed children's physical activity after the Great East Japan Earthquake 2011, targeting the following areas: Hirono, Naraha, Tomioka, Kawauchi, Okuma, Futaba, Namie, Katsurao, Iitate, Minamisoma, Tamura, Kawamata, and some hot-spots (i.e., places associated with high levels of radiation) areas (Fig. 5). To give some context, following the earthquake, the government designated the $20-\mathrm{km}$ radius around the Fukushima Daiichi Nuclear Power Plant as a "restricted area," which faced compulsory evacuation. This is an area where more people were affected by radiation than were the tsunami victims (Oe et al. 2018). Moreover, in Itagaki et al. (2017), the researchers categorized participants who exercised regularly (i.e., daily, 2-4 times a week, or once a week) as the exercise group, and participants who almost never exercised as the no exercise group. Results showed that the exercise group had significantly lower median scores than the no exercise group on the Strengths and Difficulties Questionnaire (Goodman 1997), which assesses children's emotions and behaviors (Itagaki et al. 2017).

Intervention studies of children and adolescents affected by disasters have thoroughly considered various strategies that can be used in individual cases, including psychotherapeutic techniques (Pfefferbaum et al. 2014) and 


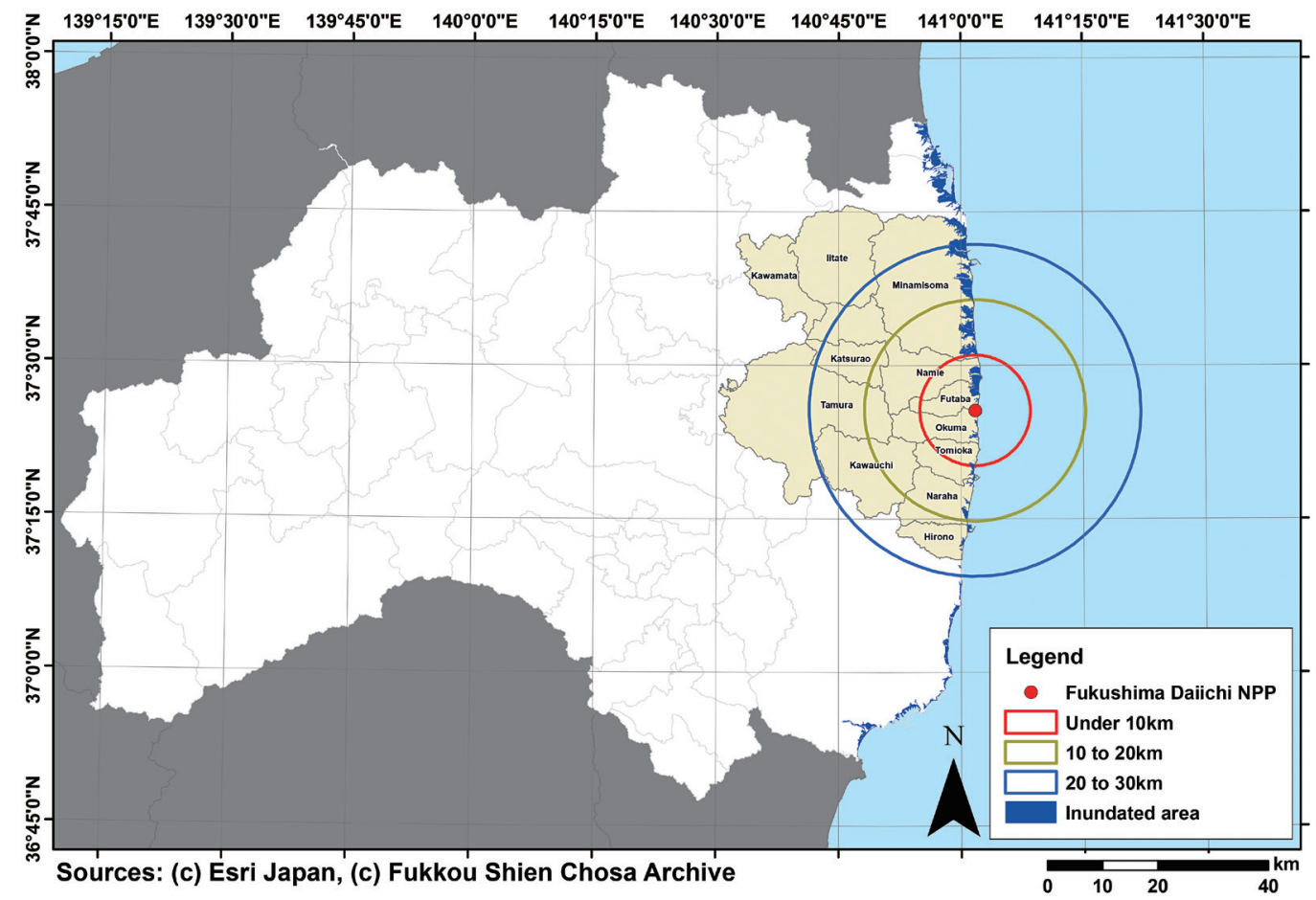

Fig. 5. Areas of radiation after the Great East Japan Earthquake and Fukushima Daiichi Nuclear Power Plant accident in Fukushima prefecture.

Tsunami and radiation damage in Fukushima following the Great East Japan Earthquake 2011 and the consequent major damage to the Fukushima Daiichi Nuclear Power Station.

Concentric circles indicate the distance from the Fukushima Daiichi Nuclear Power Station. Blue regions are places that were inundated by the tsunami caused by the Great East Japan Earthquake 2011.

a web-based intervention for adolescents affected by tornadoes (Ruggiero et al. 2015). In contrast, intervention strategies to allow for the population-based management of children in post-disaster settings have rarely been investigated. One of the few studies of the topic introduced a specific school-based intervention, called the School Therapeutic Enhancement Program, in a school district affected by Hurricane Katrina (Goldman et al. 2015). Moreover, Berkowitz et al. (2011) reported the effectiveness of the Child and Family Traumatic Stress Intervention, which focused on two key risk factors of poor social or familial support and poor coping skills, in its effort to prevent chronic PTSD within 30 days of exposure to a potentially traumatic event, such as maltreatment, victimization, and intentional or unintentional injury. Cransac-Miet et al. (2021) showed that the COVID-19-related lockdown had a negative impact on lifestyle in a representative sample of stay-at-home patients with chronic coronary syndromes. In particular, a rapid (i.e., after only 4 weeks of COVID-19related lockdown) decrease in physical activity was common.

However, one of the barriers to widespread application of such interventions relates to human resources. These types of interventions require a considerable number of staff and specialists, which also requires significant financial resources (Okuyama et al. 2017a). For example, Okuyama et al. (2017b) examined the effects of counseling for high school students suffering after the Great East Japan Earthquake 2011. Results showed that although counseling was effective against PTSD and depression, it was not effective against anxiety symptoms, and the intervention did not show any effect on some students. In conclusion, these studies demonstrate that introducing physical activity practices for children and adolescents affected by the COVID-19 pandemic may be a simple and inexpensive support method to help maintain their mental health.

\section{Limitations}

First, it would have been desirable to categorize the papers based on the type of studies - observational, longitudinal follow-ups, and intervention studies - and to discuss the relationship between physical activity and mental health. However, as shown in Fig. 4, only few papers could be included in this review. Therefore, it was not possible to classify them and discuss the findings accordingly. Second, none of the reviewed articles provided information on how many calories or what exercises/physical activities may be effective to improve mental health in children and adolescents under psychological stress. However, we acknowledge that it may be ethically problematic to create a method that includes a control group that does not receive the support given to the intervention group - a method that could help demonstrate which activity would be effective to improve mental health of this population. Third, although 
it was shown that the performance of physical activity in the outdoors/natural environments was beneficial for the mental health of children and adolescents under stress (Thompson et al. 2011), none of the reviewed articles compared the effects of indoor and outdoor physical activities.

Furthermore, our results highlighted the effect of not only physical activity but also of different mediating factors on the mental health of children and adolescents. For instance, Macdonald-Wallis et al. (2011) and Salway et al. (2018) showed that school-based friendship groups were associated with physical activity. In summary, we suggest that future studies should examine the mediating factors between physical activity and mental health.

\section{Strengths}

The major strength of this review was that it examined the possible effects of physical activity on mental health in Japanese children and adolescents affected by the school restrictions due to the COVID-19 pandemic. Currently, few studies are available on the relationship between physical activity and mental health in children and adolescents under stress. Thus, this review can serve as a theoretical framework, as well as highlighting the need for interventions that elicit physical activity among children and adolescents affected by the COVID-19-related lockdown; we suggest, based on the review, that greater levels of physical activities may improve the mental health of this population under such restricted circumstances.

Conversely, we also demonstrated that sustaining sedentary behaviors (e.g., watching TV) without regular physical activity could worsen mental health. However, previous studies have also shown that it is important not only to promote physical activity, but also to introduce interventions that lead to physical activity (Karsten 2005; Ding et al. 2011; Seto et al. 2019; Seto and Imamura 2020; Kepper et al. 2020). This is an important perspective when considering people affected by the COVID-19 related lockdown. During the lockdown, commuters may increase the use of their personal car rather than public transport, potentially reducing physical activity levels and leading to negative health and environmental effects (Brooks et al. 2020).

The geographic characteristics of Japan make the country highly vulnerable to disasters such as earthquakes, typhoons, volcanic eruptions, flash floods, and landslides (Nguyen et al. 2019). The Japanese municipal government has potentially the greatest impact on the population; therefore, it is responsible for issuing evacuation orders, opening and operating evacuation centers, and managing relief efforts. When an evacuation order is issued by a local municipality, residents who live in specific zones are mandated to evacuate (Sakurai and Adu-Gyamfi 2020). Several factors have been associated with increased COVID-19 infection rates, such as the displacement of large numbers of people into overcrowded shelters, high exposure to disease vectors, and lack of water and sanitation (Nawfal et al. 2020). To prevent some of these factors through social dis- tancing, countries have suggested or enforced the narrowing of the range of activities that are permitted in shelters, consequently reducing the amount of physical activity that may occur therein. Hence, to maintain the mental health of children and adolescents even during such distressing times (e.g., during a pandemic), we highlight the need to develop interventions to promote physical activities that can be performed in limited spaces (e.g., an evacuation center) as necessary.

\section{Conclusions}

We found through a literature review that physical activities might help reduce mental health issue among Japanese children and adolescents affected by school restrictions due to the COVID-19 pandemic. Thus, stakeholders in the mental health of children and adolescents worldwide should recommend physical activity because it is a feasible and helpful form of long-term psychological support.

\section{Acknowledgments}

The Core Research Cluster of Disaster Science in Tohoku University (Designated National University) supported this work.

\section{Conflict of Interest}

The authors declare no conflict of interest.

\section{References}

Amewu, S., Asante, S., Pauw, K. \& Thurlow, J. (2020) The economic costs of COVID-19 in Sub-Saharan Africa: insights from a simulation exercise for Ghana. Eur. J. Dev. Res., 1-26.

Ayittey, F.K., Ayittey, M.K., Chiwero, N.B., Kamasah, J.S. \& Dzuvor, C. (2020) Economic impacts of Wuhan 2019-nCoV on China and the world. J. Med. Virol., 92, 473-475.

Bao, R. \& Zhang, A. (2020) Does lockdown reduce air pollution? Evidence from 44 cities in northern China. Sci. Total Environ., 731, 139052.

Berkowitz, S.J., Stover, C.S. \& Marans, S.R. (2011) The Child and Family Traumatic Stress Intervention: secondary prevention for youth at risk of developing PTSD. J. Child Psychol. Psychiatry, 52, 676-685.

Biddle, S.J. \& Asare, M. (2011) Physical activity and mental health in children and adolescents: a review of reviews. Br. J. Sports Med., 45, 886-895.

Bolton, D., O‘Ryan, D., Udwin, O., Boyle, S. \& Yule, W. (2000) The long-term psychological effects of a disaster experienced in adolescence: II: general psychopathology. J. Child Psychol. Psychiatry, 41, 513-523.

Brener, A., Mazor-Aronovitch, K., Rachmiel, M., Levek, N., Barash, G., Pinhas-Hamiel, O., Lebenthal, Y. \& Landau, Z. (2020) Lessons learned from the continuous glucose monitoring metrics in pediatric patients with type 1 diabetes under COVID-19 lockdown. Acta Diabetol., 57, 1511-1517.

Brooks, J.H.M., Tingay, R. \& Varney, J. (2020) Social distancing and COVID-19: an unprecedented active transport public health opportunity. Br. J. Sports Med., doi: 10.1136/ bjsports-2020-102856. [Epub ahead of print].

Buchanan, M. \& Keats, P. (2011) Coping with traumatic stress in journalism: a critical ethnographic study. Int. J. Psychol., 46, 127-135.

Caldwell, K., Emery, L., Harrison, M. \& Greeson, J. (2011) 
Changes in mindfulness, well-being, and sleep quality in college students through taijiquan courses: a cohort control study. J. Altern. Complement. Med., 17, 931-938.

Carriedo, A., Cecchini, J.A., Fernández-Río, J. \& MéndezGiménez, A. (2020) Resilience and physical activity in people under home isolation due to COVID-19: a preliminary evaluation. Ment. Health Phys. Act., 19, 100361.

Ceconi, V., Barbi, E. \& Tornese, G. (2020) Glycemic control in type 1 diabetes mellitus and COVID-19 lockdown: what comes after a "quarantine"? J. Diabetes, 12, 946-948.

Chen, Y.T., Yen, Y.F., Yu, S.H. \& Chia-Yu Su, E. (2020) A flexible lockdown by integrating public health and economic reactivation to response the crisis of COVID-19: responses to comments by Alvaro J Idrovo on "An examination on the transmission of COVID-19 and the effect of response strategies: a comparative analysis". Int. J .Environ. Res. Public Health, 17, 8068.

Chu, A.H.Y., van Dam, R.M., Biddle, S.J.H., Tan, C.S., Koh, D. \& Müller-Riemenschneider, F. (2018) Self-reported domainspecific and accelerometer-based physical activity and sedentary behaviour in relation to psychological distress among an urban Asian population. Int. J. Behav. Nutr. Phys. Act., 15, 36.

Costigan, S.A., Eather, N., Plotnikoff, R.C., Hillman, C.H. \& Lubans, D.R. (2016) High-intensity interval training for cognitive and mental health in adolescents. Med. Sci. Sports Exerc., 48, 1985-1993.

Cransac-Miet, A., Zeller, M., Chagué, F., Faure, A.S., Bichat, F., Danchin, N., Boulin, M. \& Cottin, Y. (2021) Impact of COVID-19 lockdown on lifestyle adherence in stay-at-home patients with chronic coronary syndromes: towards a time bomb. Int. J. Cardiol., 323, 285-287.

Culver, K.A., Whetten, K., Boyd, D.L. \& O`Donnell, K. (2015) Yoga to reduce trauma-related distress and emotional and behavioral difficulties among children living in orphanages in Haiti: a pilot study. J. Altern. Complement. Med., 21, 539-545.

Dallavalle, G., Pezzotti, E., Provenzi, L., Toni, F., Carpani, A. \& Borgatti, R. (2020) Migraine symptoms improvement during the COVID-19 lockdown in a cohort of children and adolescents. Front. Neurol., 11, 579047.

Deng, C.H., Wang, J.Q., Zhu, L.M., Liu, H.W., Guo, Y., Peng, X.H., Shao, J.B. \& Xia, W. (2020) Association of web-based physical education with mental health of college students in Wuhan during the COVID-19 Outbreak: cross-sectional survey study. J. Med. Internet Res., 22, e21301.

Ding, D., Sallis, J.F., Kerr, J., Lee, S. \& Rosenberg, D.E. (2011) Neighborhood environment and physical activity among youth a review. Am. J. Prev. Med., 41, 442-455.

Duberg, A., Moller, M. \& Sunvisson, H. (2016) "I feel free": experiences of a dance intervention for adolescent girls with internalizing problems. Int. J. Qual. Stud. Health Well-being, 11, 31946.

Endrighi, R., Steptoe, A. \& Hamer, M. (2016) The effect of experimentally induced sedentariness on mood and psychobiological responses to mental stress. Br. J. Psychiatry., 208, 245-251.

Every-Palmer, S., Jenkins, M., Gendall, P., Hoek, J., Beaglehole, B., Bell, C., Williman, J., Rapsey, C. \& Stanley, J. (2020) Psychological distress, anxiety, family violence, suicidality, and wellbeing in New Zealand during the COVID-19 lockdown: a cross-sectional study. PLoS One, 15, e0241658.

Ezpeleta, L., Navarro, J.B., de la Osa, N., Trepat, E. \& Penelo, E. (2020) Life conditions during COVID-19 lockdown and mental health in Spanish adolescents. Int. J. Environ. Res. Public Health, 17, 7327.

Fiorillo, A., Sampogna, G., Giallonardo, V., Del Vecchio, V., Luciano, M., Albert, U., Carmassi, C., Carrà, G., Cirulli, F., Dell'Osso, B., Nanni, M.G., Pompili, M., Sani, G., Tortorella, A. \& Volpe, U. (2020) Effects of the lockdown on the mental health of the general population during the COVID-19 pandemic in Italy: results from the COMET collaborative network. Eur. Psychiatry, 63, e87.

Fu, S., Guo, M., Fan, L., Deng, Q., Han, D., Wei, Y., Luo, J., Qin, G. \& Cheng, J. (2021) Ozone pollution mitigation in guangxi (south China) driven by meteorology and anthropogenic emissions during the COVID-19 lockdown. Environ. Pollut., 272, 115927.

Gallo, L.A., Gallo, T.F., Young, S.L., Moritz, K.M. \& Akison, L.K. (2020) The impact of isolation measures due to COVID-19 on energy intake and physical activity levels in Australian university students. Nutrients, 12, 1865.

Gilic, B., Ostojic, L., Corluka, M., Volaric, T. \& Sekulic, D. (2020) Contextualizing parental/familial influence on physical activity in adolescents before and during COVID-19 pandemic: a prospective analysis. Children (Basel), 7, 125.

Giustino, V., Parroco, A. M., Antonio Gennaro, A., Musumeci, G., Palma, A. \& Battaglia, G. (2020) Physical activity levels and related energy expenditure during COVID-19 quarantine among the Sicilian active population: a cross-sectional online survey study. Sustainability, 12, 4356.

Goenjian, A.K., Khachadourian, V., Armenian, H., Demirchyan, A. \& Steinberg, A.M. (2018) Posttraumatic stress disorder 23 years after the 1988 Spitak earthquake in Armenia. J. Trauma. Stress, 31, 47-56.

Goldman, E.E., Bauer, D., Newman, D.L., Kalka, E., Lochman, J.E., Silverman, W.K., Jensen, P.S., Curry, J., Stark, K., Wells, K.C. \& Bannon, W.M.; Integrated Psychotheraphy Consortium (2015) A school-based post-Katrina therapeutic intervention. Adm. Policy Ment. Health, 42, 363-372.

Goodman, R. (1997) The strengths and difficulties questionnaire: a research note. J. Child Psychol. Psychiatry, 38, 581-586.

Gotink, R.A., Younge, J.O., Wery, M.F., Utens, E., Michels, M., Rizopoulos, D., van Rossum, L.F.C., Roos-Hesselink, J.W. \& Hunink, M.M.G. (2017) Online mindfulness as a promising method to improve exercise capacity in heart disease: 12-month follow-up of a randomized controlled trial. PLoS One, 12, e0175923.

Hiller, R.M., Meiser-Stedman, R., Fearon, P., Lobo, S., McKinnon, A., Fraser, A. \& Halligan, S.L. (2016) Research review: changes in the prevalence and symptom severity of child posttraumatic stress disorder in the year following trauma: a metaanalytic study. J. Child Psychol. Psychiatry, 57, 884-898.

Holmes, M.E., Pivarnik, J., Pfeiffer, K., Maier, K.S., Eisenmann, J.C. \& Ewing, M. (2016) The stress-metabolic syndrome relationship in adolescents: an examination of the moderating potential of physical activity. J. Phys. Act. Health, 13, 10881093.

Inada, H., Ashraf, L. \& Campbell, S. (2021) COVID-19 lockdown and fatal motor vehicle collisions due to speed-related traffic violations in Japan: a time-series study. Inj. Prev., 27, 98-100.

Isumi, A., Doi, S., Yamaoka, Y., Takahashi, K. \& Fujiwara, T. (2020) Do suicide rates in children and adolescents change during school closure in Japan? The acute effect of the first wave of COVID-19 pandemic on child and adolescent mental health. Child Abuse Negl., 110, 104680.

Itagaki, S., Harigane, M., Maeda, M., Yasumura, S., Suzuki, Y., Mashiko, H., Nagai, M., Ohira, T. \& Yabe, H.; Mental Health Group of the Fukushima Health Management Survey (2017) Exercise habits are important for the mental health of children in Fukushima after the Fukushima Daiichi disaster. Asia Pac. J. Public Health, 29, 171S-181S.

Jewett, R., Sabiston, C.M., Brunet, J., O’Loughlin, E.K., Scarapicchia, T. \& O'Loughlin, J. (2014) School sport participation during adolescence and mental health in early adulthood. $J$. Adolesc. Health, 55, 640-644.

Karako, K., Song, P., Chen, Y. \& Tang, W. (2020) Shifting workstyle to teleworking as a new normal in face of COVID-19: analysis with the model introducing intercity movement and behavioral pattern. Ann. Transl. Med., 8, 1056. 
Karsten, L. (2005) It all used to be better? Different generations on continuity and change in urban children's daily use of space. Child. Geogr., 3, 275-290.

Keays, G., Friedman, D. \& Gagnon, I. (2020) Injuries in the time of COVID-19. Health Promot. Chronic Dis. Prev. Can., 40, 336-341.

Kepper, M.M., Staiano, A.E., Katzmarzyk, P.T., Reis, R.S., Eyler, A.A., Griffith, D.M., Kendall, M.L., ElBanna, B., Denstel, K.D. \& Broyles, S.T. (2020) Using mixed methods to understand women's parenting practices related to their child's outdoor play and physical activity among families living in diverse neighborhood environments. Health Place, 62, 102292.

Khachadourian, V., Armenian, H.K., Demirchyan, A. \& Goenjian, A. (2015) Loss and psychosocial factors as determinants of quality of life in a cohort of earthquake survivors. Health Qual. Life Outcomes, 13, 13.

Kılınçel, S., Kılınçel, O., Muratdağı, G., Aydın, A. \& Usta, M.B. (2020) Factors affecting the anxiety levels of adolescents in home-quarantine during COVID-19 pandemic in Turkey. Asia Pac. Psychiatry, doi: 10.1111/appy.12406. [Epub ahead of print].

Kleppang, A.L., Thurston, M., Hartz, I. \& Hagquist, C. (2019) Psychological distress among Norwegian adolescents: changes between 2001 and 2009 and associations with leisure time physical activity and screen-based sedentary behaviour. Scand. J. Public Health, 47, 166-173.

Kwok, C.S., Gale, C.P., Curzen, N., de Belder, M.A., Ludman, P., Lüscher, T.F., Kontopantelis, E., Roebuck, C., Denwood, T., Burton, T., Hains, J., Deanfield, J.E. \& Mamas, M.A. (2020) Impact of the COVID-19 pandemic on percutaneous coronary intervention in England: insights from the British Cardiovascular Intervention Society PCI database cohort. Circ. Cardiovasc. Interv., 13, e 009654

Kyodo News (2020) School restarts picking up in Japan amid lingering coronavirus fears.

https://english.kyodonews.net/news/2020/06/bdd000c967a7school-restarts-picking-up-in-japan-amid-lingering-coronavirus-fears.html

[Accessed: August 8, 2020].

Lee, J. (2020) Mental health effects of school closures during COVID-19. Lancet Child Adolesc. Health, 4, 421.

López-Bueno, R., López-Sánchez, G.F., Casajús, J.A., Calatayud, J., Gil-Salmerón, A., Grabovac, I., Tully, M.A. \& Smith, L. (2020) Health-related behaviors among school-aged children and adolescents during the Spanish Covid-19 confinement. Front. Pediatr., 8, 573.

Lucas-Thompson, R.G., Miller, R.L., Seiter, N.S. \& Prince, M.A. (2019) Dispositional mindfulness predicts cortisol, cardiovascular, and psychological stress responses in adolescence. Psychoneuroendocrinology, 110, 104405.

Macdonald-Wallis, K., Jago, R., Page, A.S., Brockman, R. \& Thompson, J.L. (2011) School-based friendship networks and children's physical activity: a spatial analytical approach. Soc. Sci. Med., 73, 6-12.

Marazziti, D. \& Stahl, S.M. (2020) The relevance of COVID-19 pandemic to psychiatry. World Psychiatry, 19, 261.

Martikainen, S., Pesonen, A.K., Lahti, J., Heinonen, K., Feldt, K., Pyhälä, R., Tammelin, T., Kajantie, E., Eriksson, J.G., Strandberg, T.E. \& Räikkönen, K. (2013) Higher levels of physical activity are associated with lower hypothalamic-pituitaryadrenocortical axis reactivity to psychosocial stress in children. J. Clin. Endocrinol. Metab., 98, E619-627.

Maugeri, G., Castrogiovanni, P., Battaglia, G., Pippi, R., D’Agata, V., Palma, A., Di Rosa, M. \& Musumeci, G. (2020) The impact of physical activity on psychological health during Covid-19 pandemic in Italy. Heliyon, 6, e04315.

Ministry of Education, Culture, Sports, Science and Technology, Elementary and Secondary Education Bureau, Health Educa- tion and Food Education Division (2020) Status of learning and instruction in public schools based on the impact of coronavirus infection.

https://www.mext.go.jp/content/20200717-mxt_kouhou01000004520_1.pdf

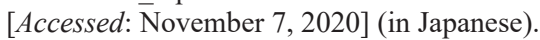

Ministry of Health, Labor and Welfare (2020) About outbreaks of patients, etc. related to the new coronavirus. https://www. mhlw.go.jp/stf/seisakunitsuite/bunya/0000164708_00001.html [Accessed: November 7, 2020] (in Japanese).

Montano, W. \& Gushiken, E. (2020) Lima soundscape before confinement and during curfew. Airplane flights suppressions because of Peruvian lockdown. J. Acoust. Soc. Am., 148, 1824.

Morgan, L., Scourfield, J., Williams, D., Jasper, A. \& Lewis, G. (2003) The Aberfan disaster: 33-year follow-up of survivors. Br. J. Psychiatry, 182, 532-536.

Naqvi, H.R., Datta, M., Mutreja, G., Siddiqui, M.A., Naqvi, D.F. \& Naqvi, A.R. (2021) Improved air quality and associated mortalities in India under COVID-19 lockdown. Environ. Pollut., 268, 115691.

Nawfal Dagher, T., Al-Bayssari, C., Diene, S.M., Azar, E. \& Rolain, J.M. (2020) Bacterial infection during wars, conflicts and post-natural disasters in Asia and the Middle East: a narrative review. Expert Rev. Anti Infect. Ther., 18, 511-529.

Nguyen, D.N., Esteban, M. \& Onuki, M. (2019) Resiliency in tourism transportation: case studies of Japanese railway companies preparing for the 2020 Tokyo Olympics. Int. J. Disaster Risk Reduct., 38, 101222

Nomura, S., Blangiardo, M., Tsubokura, M., Ochi, S. \& Hodgson, S. (2016) School restrictions on outdoor activities and weight status in adolescent children after Japan's 2011 Fukushima Nuclear Power Plant disaster: a mid-term to long-term retrospective analysis. BMJ Open, 6, e013145.

Oe, M., Maeda, M., Ohira, T., Itagaki, S., Harigane, M., Suzuki, Y., Yabe, H., Yasumura, S., Kamiya, K. \& Ohto, H. (2018) Trajectories of emotional symptoms and peer relationship problems in children after nuclear disaster: evidence from the Fukushima Health Management Survey. Int. J. Environ. Res. Public Health, 15, 82.

Okuyama, J., Funakoshi, S., Tomita, H., Yamaguchi, T. \& Matsuoka, H. (2017a) School-based interventions aimed at the prevention and treatment of adolescents affected by the 2011 Great East Japan Earthquake: a three-year longitudinal study. Tohoku J. Exp. Med., 242, 203-213.

Okuyama, J., Funakoshi, S., Tomita, H., Yamaguchi, T. \& Matsuoka, H. (2017b) Mental health and school-based intervention among adolescent exposed to the 2011 Great East Japan Earthquake and tsunami. Int. J. Disaster Risk Reduct., 24, 183-188.

Opdal, I.M., Morseth, B., Handegård, B.H., Lillevoll, K., Ask, H., Nielsen, C.S., Horsch, A., Furberg, A.S., Rosenbaum, S. \& Rognmo, K. (2019) Change in physical activity is not associated with change in mental distress among adolescents: the Tromso study: Fit Futures. BMC Public Health, 19, 916.

Padrón, A., Galán, I. \& Rodríguez-Artalejo, F. (2012) Behavioral risk factors and mental health: single and cluster associations in Spanish adolescents. J. Dev. Behav. Pediatr., 33, 698-704.

Paolucci, E.M., Loukov, D., Bowdish, D.M.E. \& Heisz, J.J. (2018) Exercise reduces depression and inflammation but intensity matters. Biol. Psychol., 133, 79-84.

Papetti, L., Loro, P.A.D., Tarantino, S., Grazzi, L., Guidetti, V., Parisi, P., Raieli, V., Sciruicchio, V., Termine, C., Toldo, I., Tozzi, E., Verdecchia, P., Carotenuto, M., Battisti, M., Celi, A., et al. (2020) I stay at home with headache. A survey to investigate how the lockdown for COVID-19 impacted on headache in Italian children. Cephalalgia, 40, 1459-1473.

Passanisi, S., Pecoraro, M., Pira, F., Alibrandi, A., Donia, V., Lonia, P., Pajno, G.B., Salzano, G. \& Lombardo, F. (2020) 
Quarantine due to the COVID-19 pandemic from the perspective of pediatric patients with type 1 diabetes: a web-based survey. Front. Pediatr., 8, 491.

Pfefferbaum, B., Sweeton, J.L., Nitiema, P., Noffsinger, M.A., Varma, V., Nelson, S.D. \& Newman, E. (2014) Child disaster mental health interventions: therapy components. Prehosp. Disaster Med., 29, 494-502.

Phillips, S.P., Reipas, K. \& Zelek, B. (2019) Stresses, strengths and resilience in adolescents: a qualitative study. J. Prim. Prev., 40, 631-642.

Picchio, C.A., Valencia, J., Doran, J., Swan, T., Pastor, M., Martró, E., Colom, J. \& Lazarus, J.V. (2020) The impact of the COVID-19 pandemic on harm reduction services in Spain. Harm Reduct. J., 17, 87.

Rodriguez-Ayllon, M., Cadenas-Sanchez, C., Esteban-Cornejo, I., Migueles, J.H., Mora-Gonzalez, J., Henriksson, P., MartínMatillas, M., Mena-Molina, A., Molina-García, P., EstévezLópez, F., Enriquez, G.M., Perales, J.C., Ruiz, J.R., Catena, A. \& Ortega, F.B. (2018) Physical fitness and psychological health in overweight/obese children: a cross-sectional study from the ActiveBrains project. J. Sci. Med. Sport, 21, 179-184.

Rubin, G.J. \& Wessely, S. (2020) The psychological effects of quarantining a city. $B M J, \mathbf{3 6 8}, \mathrm{m} 313$.

Ruggiero, K.J., Price, M., Adams, Z., Stauffacher, K., McCauley, J., Danielson, C.K., Knapp, R., Hanson, R.F., Davidson, T.M., Amstadter, A.B., Carpenter, M.J., Saunders, B.E., Kilpatrick, D.G. \& Resnick, H.S. (2015) Web intervention for adolescents affected by disaster: population-based randomized controlled trial. J. Am. Acad. Child Adolesc. Psychiatry, 54, 709-717.

Sagatun, A., Søgaard, A.J., Bjertness, E., Selmer, R. \& Heyerdahl, S. (2007) The association between weekly hours of physical activity and mental health: a three-year follow-up study of 15-16-year-old students in the city of Oslo, Norway. BMC Public Health, 7, 155.

Sagatun, Å., Wentzel-Larsen, T., Heyerdahl, S. \& Lien, L. (2016) Mental health in adolescence and subsequent receipt of medical benefits in young adulthood: the mediating role of upper secondary school completion. Scand. J. Public Health, 44, 431-438.

Sakurai, M. \& Adu-Gyamfi, B. (2020) Disaster-resilient communication ecosystem in an inclusive society: a case of foreigners in Japan. Int. J. Disaster Risk Reduct., 51, 101804.

Salway, R.E., Sebire, S.J., Solomon-Moore, E., Thompson, J.L. \& Jago, R. (2018) Associations within school-based same-sex friendship networks of children's physical activity and sedentary behaviours: a cross-sectional social network analysis. Int. J. Behav. Nutr. Phys. Act., 15, 18.

Seto, S. \& Imamura, F. (2020) Classification of tsunami deaths by modifying ICD-10 categories in the 2011 Tohoku earthquake tsunami: a case study in Miyagi prefecture. Int. J. Disaster Risk Reduct., 50, 101743.

Seto, S., Imamura. F. \& Suppasri, A. (2019) Challenge to build the science of human survival from disaster staring from analysis for the 2011 Tohoku Tsunami. J. Disaster Res., 14, 13231328.

Shah, K., Mann, S., Singh, R., Bangar, R. \& Kulkarni, R. (2020) Impact of COVID-19 on the mental health of children and adolescents. Cureus, 12, e10051.

Shahidi, S.H., Stewart Williams, J. \& Hassani, F. (2020) Physical activity during COVID-19 quarantine. Acta Paediatr., 109, 2147-2148

Shibata, S. (2020) The impact from COVID-19 pandemic on the practice of child and adolescent psychiatry. Jpn. J. Clin. Psychatry, 49, 1525-1529.

Shigemura, J., Ursano, R.J., Morganstein, J.C., Kurosawa, M. \& Benedek, D.M. (2020) Public responses to the novel 2019 coronavirus (2019-nCoV) in Japan: mental health conse- quences and target populations. Psychiatry Clin. Neurosci., 74, 281-282.

Sloan, R.A., Sawada, S.S., Girdano, D., Liu, Y.T., Biddle, S.J. \& Blair, S.N. (2013) Associations of sedentary behavior and physical activity with psychological distress: a cross-sectional study from Singapore. BMC Public Health, 13, 885.

Slootmaker, S.M., Schuit, A.J., Chinapaw, M.J., Seidell, J.C. \& van Mechelen, W. (2009) Disagreement in physical activity assessed by accelerometer and self-report in subgroups of age, gender, education and weight status. Int. J. Behav. Nutr. Phys. Act., 6, 17.

Smirni, P., Lavanco, G. \& Smirni, D. (2020) Anxiety in older adolescents at the time of COVID-19. J Clin Med, 9, 3064.

Stewart, H., Watson, N. \& Campbell, M. (2018) The cost of school holidays for children from low income families. Childhood, 25, 516-529.

Tajik, E., Abd Latiff, L., Adznam, S.N., Awang, H., Yit Siew, C. \& Abu Bakar, A.S. (2017) A study on level of physical activity, depression, anxiety and stress symptoms among adolescents. J. Sports Med. Phys. Fitness, 57, 1382-1387.

Thompson Coon, J., Boddy, K., Stein, K., Whear, R., Barton, J. \& Depledge, M.H. (2011) Does participating in physical activity in outdoor natural environments have a greater effect on physical and mental wellbeing than physical activity indoors? A systematic review. Environ. Sci. Technol., 45, 1761-1772.

Thompson, T., Zieba, B., Howell, S., Karakash, W. \& Davis, S. (2020) A mixed methods study of physical activity and quality of life in adolescents with Turner syndrome. Am. J. Med. Genet. A, 182, 386-396.

Tonorezos, E.S., Ford, J.S., Wang, L., Ness, K.K., Yasui, Y., Leisenring, W., Sklar, C.A., Robison, L.L., Oeffinger, K.C., Nathan, P.C., Armstrong, G.T., Krull, K. \& Jones, L.W. (2019) Impact of exercise on psychological burden in adult survivors of childhood cancer: a report from the Childhood Cancer Survivor Study. Cancer, 125, 3059-3067.

Townsend, E. (2020) Debate: the impact of school closures and lockdown on mental health in young people. Child Adolesc. Ment. Health, 25, 265-266.

Tromans, S., Chester, V., Harrison, H., Pankhania, P., Booth, H. \& Chakraborty, N. (2020) Patterns of use of secondary mental health services before and during COVID-19 lockdown: observational study. BJPsych Open, 6, e117.

Udwin, O., Boyle, S., Yule, W., Bolton, D. \& O'Ryan, D. (2000) Risk factors for long-term psychological effects of a disaster experienced in adolescence: predictors of post traumatic stress disorder. J. Child Psychol. Psychiatry, 41, 969-979.

Vandendriessche, A., Ghekiere, A., Van Cauwenberg, J., De Clercq, B., Dhondt, K., DeSmet, A., Tynjälä, J., Verloigne, M. \& Deforche, B. (2019) Does sleep mediate the association between school pressure, physical activity, screen time, and psychological symptoms in early adolescents? A 12-Country Study. Int. J. Environ. Res. Public Health, 16, 1072.

Vankim, N.A. \& Nelson, T.F. (2013) Vigorous physical activity, mental health, perceived stress, and socializing among college students. Am. J. Health Promot., 28, 7-15.

Vierucci, F., Bacci, C., Mucaria, C., Dini, F., Federico, G., Maielli, M. \& Vaccaro, A. (2020) How COVID-19 pandemic changed children and adolescents use of the Emergency Department: the experience of a secondary care pediatric unit in central Italy. SN Compr. Clin. Med., 2, 1959-1969.

Wang, C., Pan, R., Wan, X., Tan, Y., Xu, L., McIntyre, R.S., Choo, F.N., Tran, B., Ho, R., Sharma, V.K. \& Ho, C. (2020a) A longitudinal study on the mental health of general population during the COVID-19 epidemic in China. Brain Behav. Immun., 87, 40-48.

Wang, G., Zhang, Y., Zhao, J., Zhang, J. \& Jiang, F. (2020b) Mitigate the effects of home confinement on children during the COVID-19 outbreak. Lancet, 395, 945-947.

Wang, S.T. \& Xu, K.F. (2020) Response to: hydrogen therapy as 
an effective and novel adjuvant treatment against COVID-19.

World Health Organization (2004) The importance of caregiverchild interactions for the survival and healthy development of young children: A review, WHO, Geneva, Switzerland.

World Health Organization (2010) World Health Organization Global Recommendations on Physical Activity for Health, WHO, Geneva, Switzerland.

Yule, W., Bolton, D., Udwin, O., Boyle, S., O’Ryan, D. \& Nurrish, J. (2000) The long-term psychological effects of a disaster experienced in adolescence: I: the incidence and course of PTSD. J. Child Psychol. Psychiatry, 41, 503-511.

Zhang, X., Zhu, W., Kang, S., Qiu, L., Lu, Z. \& Sun, Y. (2020) Association between physical activity and mood states of chil- dren and adolescents in social isolation during the COVID-19 epidemic. Int. J. Environ. Res. Public Health, 17, 7666.

Zhao, G., Li, C., Li, J. \& Balluz, L.S. (2013) Physical activity, psychological distress, and receipt of mental healthcare services among cancer survivors. J. Cancer Surviv., 7, 131-139.

Zhou, J., Yuan, X., Qi, H., Liu, R., Li, Y., Huang, H., Chen, X. \& Wang, G. (2020a) Prevalence of depression and its correlative factors among female adolescents in China during the coronavirus disease 2019 outbreak. Global. Health, 16, 69.

Zhou, M., Zhang, X. \& Qu, J. (2020b) Coronavirus disease 2019 (COVID-19): a clinical update. Front. Med., 14, 126-135. 